\title{
Blockade of NMDA Receptors in Prelimbic Cortex Induces an Enduring Amnesia for Odor-Reward Associative Learning
}

\author{
Sophie Tronel and Susan J. Sara \\ Neuromodulation and Memory Processes, Unité Mixte de Recherche 7102, Centre National de la Recherche Scientifique, Université Pierre et Marie Curie, \\ 75005 Paris, France
}

The competitive antagonist 2-amino-5-phosphonoeptanoic acid (APV) was injected intracerebroventricularly to determine the involvement of NMDA receptors in different stages of memory consolidation. Subsequent experiments used local injections to determine possible sites of drug action. Rats were trained in a rapidly learned olfactory task to find palatable food in a hole in a sponge impregnated with the target odor in the presence of two other sponges with nonrewarded odors. APV injections were made intracerebroventricularly $5 \mathrm{~min}$ or $2 \mathrm{hr}$ after the end of the training, and a retention test was given $48 \mathrm{hr}$ later. The results showed that blockade of NMDA receptors immediately after training induces a profound and enduring amnesia with no effect when the treatment is delayed at $2 \mathrm{hr}$ after training. To address the question of the effective sites of action of the intracerebroventricular treatment, APV injections into the hippocampus and into the prelimblic region of the frontal cortex (PLC) were made. Blockade of NMDA receptors into the PLC but not into the hippocampus impaired memory formation of the odor-reward association. The amnesia is not transient, because the retention tests were made $48 \mathrm{hr}$ after training. These results underlie the role of NMDA receptors in the early stage of consolidation of a simple odor-reward associative memory and confirm the role of the PLC in the consolidation of long-term memory.

Key words: memory consolidation; prelimbic cortex; NMDA receptors; amnesia; APV; olfactory memory

\section{Introduction}

Interest in the role of NMDA receptors (NMDARs) in memory stems primarily from extensive evidence that these receptors are essential to the induction of long-term potentiation (LTP). Because it is widely held that LTP somehow underlies memory, the hypothesis for a role for NMDARs in memory formation is inevitable. Some support comes from the demonstration of a parallelism between the effectiveness of NMDAR antagonists in blocking LTP induction and preventing formation of spatial memories (Morris et al., 1986). More recent studies have extended this by showing that transgenic mice lacking NMDARs in the CA1 region of the hippocampus show both defective LTP and spatial cognition (Tsien et al., 1996). Although both approaches underline the functional role of NMDARs in the hippocampus in spatial cognition, the spatiotemporal involvement of NMDARs in postacquistion memory consolidation remains relatively unexplored. As McGaugh (1989) has argued, pharmacological effects on consolidation should be evaluated using posttrial treatments to rule out confounding effects on acquisition. Here the literature is surprisingly sparse concerning NMDARs, with few studies meeting this requirement. In a study by Packard and Teather (1997), rats were injected with the NMDAR antagonist MK-801

\footnotetext{
Received Feb. 11, 2003; revised April 29, 2003; accepted May 1, 2003.

This work was supported by Centre National de la Recherche Scientifique, Unité Mixte de Recherche 7102. We thank Y. Moricard and M. Torras for their helpful comments on this manuscript.

Correspondence should be addressed to Dr. Susan J. Sara, Neuromodulation and Memory Processes, Unité Mixte de Recherche 7102, Université Pierre et Marie Curie, 9 Quai St. Bernard, 75005 Paris, France. E-mail: sjsara@ccr.jussieu.fr.

Copyright $\odot 2003$ Society for Neuroscience $\quad$ 0270-6474/03/235472-05\$15.00/0
}

((+)-5-methyl-10,11-dihydro-5H-dibenzo [a,d] cyclohepten5,10 -imine maleate) either immediately or $2 \mathrm{hr}$ after training in spatial and nonspatial versions of the Morris water maze. Memory deficits were observed in the immediate but not in the $2 \mathrm{hr}$ group, when rats were tested $24 \mathrm{hr}$ later. There have also been a few reports of amnesia in a passive avoidance task induced by posttrial injections of the antagonist 2-amino-5-phosphonovalerate (APV) into the hippocampus or the amygdala (Ferreira et al., 1992; Liang et al., 1994; Zanatta et al., 1996). In all of these studies, animals were tested $24 \mathrm{hr}$ after training and treatment. A recent study using systemic treatment with the NMDAR antagonist $\mathrm{D}(-)-3-(2-$ carboxypiperazine-4-yl)-propyl-1-phosphonic acid (CPP) during extinction suggested that amnesia seen $24 \mathrm{hr}$ later was transient; no amnesia was seen in animals tested $48 \mathrm{hr}$ after extinction and drug treatment (Santini et al., 2001). The authors suggest that this "rescued memory" at $48 \mathrm{hr}$ argues for the existence of late waves of NMDA activity promoting memory consolidation.

In the present experiments, the effect of APV immediately or 2 hr after acquisition of an odor-reward association was evaluated. To ensure that the amnesia was enduring, retention tests were made $48 \mathrm{hr}$ after training. The odor discrimination task is well suited for the study of time-dependent memory consolidation because it is rapidly learned in three massed trials, yielding a reliable memory trace for at least 1 week.

In subsequent experiments aimed at determining the effective site of APV action, injections were made into the hippocampus or prelimbic region of the prefrontal cortex (PLC). Previous results showed modification of NMDARs after this olfactory discrimination learning in the hippocampus (Roullet et al., 1999), and NMDARs in this region have been implicated in consolidation of 
other memories (Jerusalinsky et al., 1992). The PLC was of particular interest because immunohistochemical studies of c-Fos activation suggested a massive activation of this region during or after this olfactory training (Tronel and Sara, 2002). This has been confirmed recently by electrophysiological results showing activation of a population of neurons in the PLC during learning of this task (Kublik and Sara, 2002).

\section{Materials and Methods}

Animals. Thirty-nine male Sprague Dawley rats (200-220 gm; IFFACredo, Arbresle, France) were housed in pairs in wire mesh cages $(35 \times$ $20 \times 18 \mathrm{~cm}$ ) in a temperature- and light-controlled vivarium on a $12 \mathrm{hr}$ light/dark cycle. Rats were weighed and handled daily and had access to food and water ad libitum, except during the pretraining, training, and test days, when food was restricted to $15 \mathrm{gm} / \mathrm{d}$ per rat to maintain body weight at $\sim 90 \%$ of free-feeding weight.

Surgery. One week after arrival, rats were anesthetized with pentobarbital $(60 \mathrm{mg} / \mathrm{kg})$, mounted in a stereotaxic apparatus, and implanted bilaterally with stainless steel cannulas constructed from 24 gauge stainless steel tubes cut to $11 \mathrm{~mm}$ length. Holes were drilled in the skull, and cannulas were placed just over the ventricles $[1 \mathrm{~mm}$ posterior to bregma; $\pm 2 \mathrm{~mm}$ lateral to the midline; $3 \mathrm{~mm}$ ventral to the surface of the skull; according to the atlas of Paxinos and Watson (1986)]. Three skull screws maintained the cannula, secured with dental cement. A thin stainless steel wire was placed inside each cannula to prevent blockage.

Pharmacological treatment. The fine wire was removed and replaced by the injection cannula, constructed from 36 gauge stainless steel tubing cut to $12 \mathrm{~mm}$ length. The larger tube was inserted into a catheter, which was attached to a $10 \mu \mathrm{l}$ Hamilton syringe. The injection volumes were 3 $\mu$ l per side, delivered over a period of $1 \mathrm{~min}$ while the rat was held gently in the hand of the experimenter. The injection cannula was left in position to minimize backing up of the injection fluid into the guide cannula. Control rats were injected with a vehicle solution $(0.9 \mathrm{gm}$ of $\mathrm{NaCl}, 4.5 \mathrm{ml}$ of $\mathrm{NaHPO}_{4}, 0.2 \mathrm{M}$ and $0.95 \mathrm{ml}$ of $\mathrm{NaH}_{2} \mathrm{PO}_{4} \cdot 2 \mathrm{H}_{2} \mathrm{O}, 0.2 \mathrm{M}$ in $100 \mathrm{ml}$ of $\mathrm{dH}_{2} \mathrm{O}$ ). Experimental rats were injected with APV (Sigma, St. Louis, $\mathrm{MO})$ at a concentration of $4 \mu \mathrm{g} / 3 \mu \mathrm{l}$.

Apparatus. The training apparatus and behavioral procedure have been described previously (Tronel and Sara, 2002). A square box of opaque plastic measuring $60 \times 60 \times 40 \mathrm{~cm}$ contained sponges $(6 \times 7 \times$ $2 \mathrm{~cm}$ ) with a hole of $2 \mathrm{~cm}$ diameter cut into the center, placed in glass slide holders of the same size. The food reinforcement was placed at the bottom of the opening in the sponge so the rat had to poke its snout into the hole (nose poke) to obtain the reward: chocolate rice crispy breakfast cereal (Chocopops; Kellog's). On the first trial, four Chocopops were also placed on the corners of that sponge impregnated with the target odor, as well as in the hole. The sponges with the nontarget odors did not contain food. Sponges were placed in three corners of the box, and the position of each odor within the box was changed for each trial according to a previously determined protocol. The actual set of sponges was changed between trials as well, to preclude identification based on visual cues. Sponges were impregnated with $15 \mu \mathrm{l}$ of essence on each corner. Odors used were almond, mint, and lemon; previous experiments showed that rats did not show any particular preference for or aversion to any of these odors.

A video camera was fixed above the apparatus, and the rat was observed on a video monitor in the same room. The session was recorded on video tape for additional analysis offline.

Experimental design and behavioral procedures. Rats were handled and weighed daily during the recovery period. The experiment began with $2 \mathrm{~d}$ of pretraining to familiarize the reinforcement and the experimental box. On the first day, rats were given ad libitum access to the reward for $20 \mathrm{~min}$ in a neutral cage and, on the second day, for $10 \mathrm{~min}$ in the same neutral cage and then placed $10 \mathrm{~min}$ in the experimental box without the sponges.

Training was performed the next day in a single three-trial session. Cage mates were kept in a holding cage, and one rat was introduced into the behavioral apparatus, in the corner without a sponge, head toward the wall. There was a $5 \mathrm{~min}$ ceiling for the rat to find and consume the reinforcement. Intertrial intervals were $2-5 \mathrm{~min}$. The spatial configuration of the sponges was changed between trials, and the reinforcement was always associated with the same odor. Latency before a correct response (nose poke into the reinforced sponge) and errors (nose poke into incorrect sponges or sniffing the target odor not followed by a nose poke) were noted.

Animals were assigned to treatment groups according to their performance during training. Rats were injected with the vehicle, $5 \min (n=9)$ or $2 \mathrm{hr}(n=9)$, or with APV, $5 \mathrm{~min}(n=10)$ or $2 \mathrm{hr}(n=11)$ after training. The injections were made in a quiet room, adjacent to the experimental room.

Retention test. Forty-eight hours after training, rats were tested for retention and relearning using the same procedure, except that the first test trial was not reinforced and there was a total of four trials. The first trial served as a direct a measure of memory of the previous training. Because the first trial was not reinforced, the second trial reflected resistance to extinction, which is considered as an indirect but more sensitive measure of retention. The last two trials were an index of the rats relearning ability. Latency to nose poke as well as errors of commission (nose poke to a nontarget odor) and omission (failure to nose poke after sniffing a sponge containing the target odor) were scored by an experimenter blind to the treatment groups.

Rats were anesthetized with an overdose of pentobarbital and injected with methyl blue. Brains were removed and examined for the presence of blue in the third ventricle. All rats had correctly placed cannulas and successful control injections.

Data analysis. Latency to nose poke and number of errors were taken as the performance measure. The experiment was run in two replications. Acquisition scores for the entire data set, in terms of latencies and number of errors, were submitted to an ANOVA for repeated measures. There was no effect of replication; therefore, the data were pooled for subsequent analysis.

Test scores for each rat were averaged for the two retention trials and the two relearning trials, and the data were submitted to a $2 \times 2 \times 3$ ANOVA with repeated measures (last training trial, test, and relearning) on one factor. The two other independent factors were drug treatment (APV or vehicle) and training-treatment delay ( $5 \mathrm{~min}$ or $2 \mathrm{hr}$ ). ANOVA was complemented by planned comparisons using the Newman-Keuls procedure.

\section{Results}

\section{Task acquisition}

On the third trial, there was a significant decrease in latency to find the correct sponge and make the nose poke response. The rats sniffed the edges of the sponges and rarely made a nose poke error by the third trial.

\section{Test and relearning}

The mean latency for each treatment group on the last trial of training, the two test trials, and on the two relearning trials can be seen in Figure 1. A three-way ANOVA for repeated measures was applied to these data, one factor being drug treatment, one factor being time of injection, and the repeated factor being training, retention, and relearning. The main effect of drug and time of injection approached significance $\left(F_{(1,35)}=3.47, p=0.07\right.$; $F_{(1,35)}=3.8, p=0.056$, respectively), but, most important, there was a highly significant drug $\times$ injection time interaction $\left(F_{(1,35)}=\right.$ $14.72 ; p=0.0005)$. Planned orthogonal comparisons using the Newman-Keuls procedure revealed a significant difference between the control and APV 5 min groups at the test trial $(p<$ $0.01)$. The APV 5 min group was significantly different from the APV $2 \mathrm{hr}$ group, as well $(p<0.01)$. There were no differences between the retention and the relearning for the control $5 \mathrm{~min}$ group and the control $2 \mathrm{hr}$ group. At relearning, there was still a significant deficit in the APV 5 min group, as shown in Figure 1 $(p<0.01)$. 


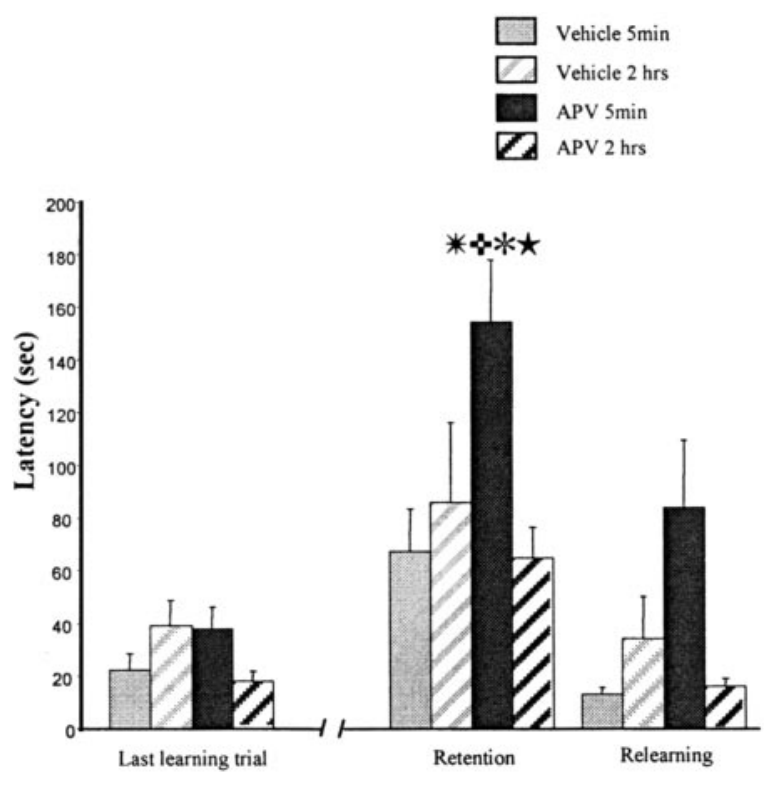

Figure 1. Intracerebroventricular injections of APV. Latency to make the correct response over the last training trial, the retention, and the relearning. Independent groups were treated $5 \mathrm{~min}$ or $2 \mathrm{hr}$ after training with APV or vehicle solution. The retention test was made $48 \mathrm{hr}$ later. The APV 5 min group is significantly different from the vehicle 5 min group ( $* p<0.01$ ) and the APV $2 \mathrm{hr}$ group $(* p<0.01)$. Significant differences were observed between the last trial of training and the retention test for the APV 5 min group ( $* p<0.01$ ) and between the retention test and the relearning $(\star p<0.01)$. Together, these data indicate that blockade of NMDA receptors immediately after training (1) induces amnesia with no effect when the treatment is $2 \mathrm{hr}$ after training and (2) does not block the relearning.

A similar pattern of results is seen when errors are considered as the performance measure. The data were analyzed as described above for latencies. There was a significant effect of the drug $\left(F_{(1,35)}=8.67 ; p=0.005\right)$, a significant effect of time interval after training $\left(F_{(1,35)}=12.81 ; p=0.001\right)$, and a significant drug $\times$ injection time $\left(F_{(1,35)}=4.29 ; p=0.04\right)$. Planned orthogonal comparisons revealed that the APV 5 min group made significantly more errors at the test than the APV 2 hr group $(p<$ $0.01)$.

\section{In situ experiments}

In an attempt to ascertain a site of drug action causing the memory deficit, two additional experiments were performed. Injections were made into the hippocampus or the PLC after the same behavioral protocol ( $1 \mu \mathrm{l}$ per side for both structures; concentration, $2.5 \mu \mathrm{g} / \mu \mathrm{l})$. The effect of an NMDA antagonist in the hippocampus was of interest because previous experiments from our laboratory showed a downregulation of these receptors in this region after this odor discrimination task (Roullet et al., 1999). The prelimbic cortex was targeted because our previous studies showed massive increases in c-Fos in rats trained in this task (Tronel and Sara, 2002).

Fourteen rats were used for the hippocampus experiment (APV, $n=8$; vehicle, $n=6$ ) and twenty-four (APV, $n=12$; vehicle, $n=12$ ) for the PLC. Surgery was the same as described above, except for the position the cannulas: $3.6 \mathrm{~mm}$ posterior to bregma, $2 \mathrm{~mm}$ lateral to the midline, and $3 \mathrm{~mm}$ below the surface of the skull for the hippocampus; and $3.2 \mathrm{~mm}$ anterior to bregma, $0.6 \mathrm{~mm}$ lateral to the midline, and $3 \mathrm{~mm}$ below the surface of the skull for the PLC (Paxinos and Watson, 1986). Rats were injected with vehicle or APV, 5 min after the training, and tested $48 \mathrm{hr}$ using the same behavioral protocol.
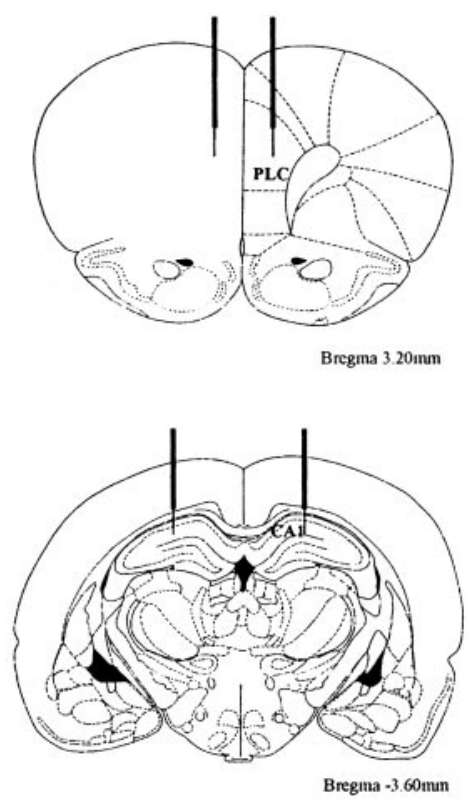

Figure 2. Position of the cannulas and injection site. Top, Cannulas in the PLC (field CA1). Bottom, Cannulas in the hippocampus.

At the end of the experiments, rats were anesthetized and injected with methyl blue. Brains were removed, frozen, sectioned, and inspected for cannula placement and for the presence of dye in the hippocampus or the PLC.

\section{Injections into the hippocampus}

All rats had cannulas placed as illustrated in Figure 2 (bottom); control dye injections were in the dorsal hippocampus. There were no differences in either terms of latency or errors between the two groups after an injection into the hippocampus. Data were submitted to a $2 \times 3$ ANOVA with repeated measures. One factor was the drug treatment, and the repeated factor was the last trial of training, the retention, and the relearning. For latencies, there was no drug effect $\left(F_{(1,12)}=0.66 ; p=0.43\right)$ or repetition effect $\left(F_{(2,24)}=11.38, p=0.0003\right.$; but no interaction $F_{(2,24)}=$ $0.03, p=0.96)$. Planned orthogonal comparisons revealed no difference between the control and APV group at the test trial and no difference between the last trial of training and the test trial for the APV group (Fig. 3). A similar pattern of results was seen for the errors; no effect of the treatment $\left(F_{(1,12)}=2.01 ; p=\right.$ $0.18)$ and no interaction $\left(F_{(2,24)}=0.97 ; p=0.4\right)$.

\section{Injections into the PLC}

All rats had cannulas situated in the region illustrated in Figure 2 (top); control dye injections were restricted to the prelimbic region of the frontal cortex. Injections of APV into the PLC produced amnesia when rats were tested $48 \mathrm{hr}$ later (Fig. 4). A twoway ANOVA for repeated measures was applied to the latency; there was a significant effect of repetition $\left(F_{(2,44)}=3.2 ; p<\right.$ $0.001)$ and a significant interaction of drug $\times$ trials $\left(F_{(2,44)}=5.4\right.$; $p<0.005)$. Planned orthogonal comparisons revealed a significant difference between control and APV groups at the test trial $(p<0.01)$ and a significant difference between the last training trial and the test trial for APV group $(p<0.01)$. A similar pattern of results was seen for the errors; a significant effect of repetition $\left(F_{(2,44)}=17.01 ; p<0.001\right)$ and a significant drug $\times$ trials interaction $\left(F_{(2,44)}=5.19 ; p<0.009\right)$. The Newman-Keuls test revealed a significant difference between control and APV groups at 


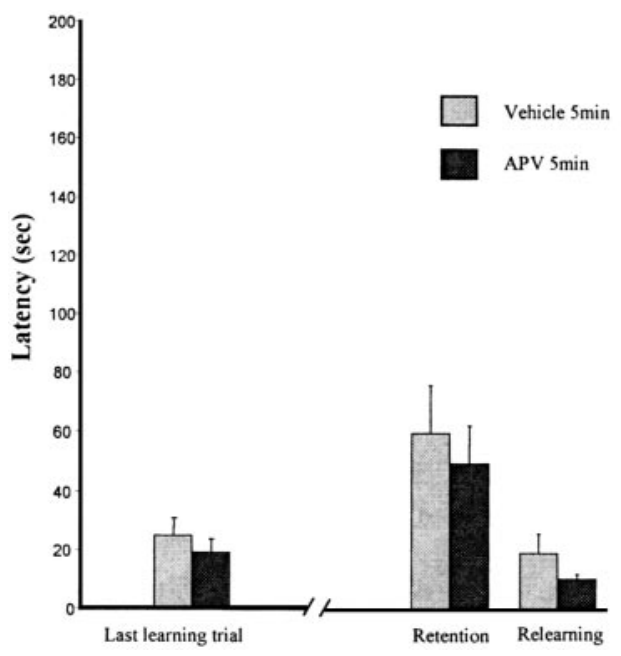

Figure 3. APV injections into the hippocampus. Latency to make the correct response over the last training trial, the retention, and the relearning. Groups were treated 5 min after training with APV or vehicle solution. The retention test was made $48 \mathrm{hr}$ later. No difference was observed between groups and between the last learning trial, the retention test, and the relearning. These data indicate that blockade of NMDA receptors into the hippocampus does not impair the memory formation of the odor-reward association.

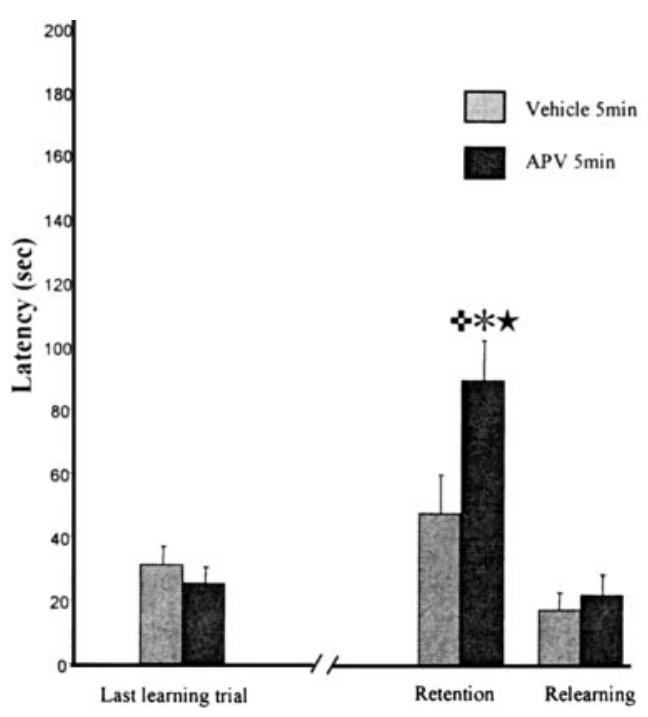

Figure 4. APV injections into the prelimbic cortex. Latency to make the correct response over the last training trial, the retention, and the relearning. Groups were treated 5 min after training with APV or vehicle solution. The retention test was made $48 \mathrm{hr}$ later. The APV group is significantly different from the vehicle group at the retention test $(-p<0.01)$. Significant differences were observed between the retention test and the last learning trial $(* x p<0.01)$ and between the retention test and the relearning ( $\star p<0.01$ ) for the APV group. These data suggest that blockade of NMDA receptors into the prelimbic cortex after the training induces amnesia but does not block the relearning.

the test trial $(p<0.01)$ and a significant difference between the last training trial and the test trial for APV group $(p<0.01)$.

\section{Discussion}

The NMDA receptor antagonist APV, injected into the lateral ventricles immediately after training on a simple odorreinforcement association task, induces a profound and enduring amnesia. Moreover, rats injected with APV were slow at relearning, suggesting a global amnesia for all elements of the training situation and not merely the odor-reward association. The effects are time dependent, in that there is no effect of the antagonist injected $2 \mathrm{hr}$ after training. This supports the notion that NMDA receptors are involved in the early stages of memory consolidation (Mayford et al., 1995; Sara et al., 1999).

\section{Durability of the amnesia}

Most previous studies showing clear amnesia induced by NMDA receptor blockade have tested animals at a $24 \mathrm{hr}$ treatment-to-test interval and have not looked for recovery at a later time point. One exception to this is a report that posttrial injections of APV into the medial prefrontal cortex, at the dose used in the present experiments, yielded no amnesia $24 \mathrm{hr}$ later but an impairment at $21 \mathrm{~d}$ (Liang et al., 1996). This accelerated forgetting after posttrial APV treatment merits further investigation. On the other hand, Santini et al. (2001) observed no amnesia at $48 \mathrm{hr}$ after training and treatment, whereas in another group of rats, there was robust amnesia at $24 \mathrm{hr}$. They suggest that the "rescue" of memory $48 \mathrm{hr}$ after treatment is evidence for a second, delayed consolidation process; it, too, is dependent on NMDA receptors but independent of the first round of consolidation. When the effects of the drug have worn off, the NMDA receptors are again available to participate in the consolidation of the weak memory. This is reminiscent of Tsien's model, suggesting that NMDA receptors are repeatedly reactivated during an on-going long-term memory consolidation process (Shimizu et al., 2000; Wittenberg and Tsien, 2002). Although this dynamic view of long-term memory formation is quite appealing, our data do not support it, at least within the $48 \mathrm{hr}$ time frame we examined. Although the present experiments were not specifically aimed at evaluating the persistence of amnesia induced by NMDA antagonists, the effects do not appear to be transient. Robust and reliable amnesia is observed $48 \mathrm{hr}$ after injection. Nevertheless, it is always possible, considering the Tsien model, that there could be spontaneous recovery of memory at some later time. However, for the present, the rescue of memory $48 \mathrm{hr}$ after systemic treatment with CPP, as observed by Santini et al. (2001), seems to be specific to their experimental paradigm, i.e., memory for extinction of conditioned fear. It cannot be ruled out, however, that differences concerning the persistence of amnesia could be attributable to differences in pharmacokinetics of the drugs used.

\section{Site of action}

Injections of APV into the prelimbic region of frontal cortex induce a reliable amnesia, but it is less severe than that seen after intracerebroventricular injections. Unlike the latter, rats amnestic after PLC injections show rapid relearning of the task. This involvement of the PLC in consolidation of an olfactory memory is not surprising given that anatomical studies reveal reciprocal connections between the piriform cortex and the prelimbic, infralimbic, and orbital regions of the PLC. These regions are thought to act in concert to link sensory, in this case olfactory, and emotional (reward) information (Datiche and Cattarelli, 1996; Ongur and Price, 2000). Furthermore, the present pharmacological results are consistent with our recent immunohistochemical results showing c-Fos activation in the same prelimbic region after learning this task. Interestingly, the two other regions showing clear differences in posttraining c-Fos, between trained and pseudotrained rats, are the orbital frontal cortex and the basal lateral amygdala (Tronel and Sara, 2002). The latter region has strong reciprocal connections to PLC and olfactory cortex, so we should expect that it is part of the neural circuit underlying the formation of a long-term odor-reward associative memory trace. 
APV injections into the dorsal hippocampus have no effect on retention measured $48 \mathrm{hr}$ later, a result consistent with the observation that hippocampal regions showed no learning-related c-Fos activity (Tronel and Sara, 2002). The results of both series of experiments lend support to Eichenbaum's claim that the hippocampus is not involved in simple olfactory associative learning (Dusek and Eichenbaum, 1998). Because others have reported amnesic effects of posttrial intrahippocampal injections after passive avoidance training (Izquierdo et al., 1992; Jerusalinsky et al., 1992) or after learning of spatial and visual versions of the water maze (Packard and Teather, 1997), the involvement of NMDA receptors in the hippocampus in the early stages of consolidation is most likely a function of the behavioral task.

In conclusion, the present series of experiments confirm the role of the prelimbic region of the frontal cortex in the consolidation of long-term memory for an odor-reward association. Such a role has already been suggested by results of c-Fos immunohistochemical studies (Tronel and Sara, 2002) and by electrophysiological studies of posttrial activation of prelimbic neurons during such learning (Kublik and Sara, 2002). NMDA receptors play an essential role in this consolidation process, because blockade of these receptors just after training induces a long-lasting amnesia for the odor-reward association.

\section{References}

Datiche F, Cattarelli M (1996) Reciprocal and topgraphic connections between the piriform and prefrontal cortices in the rat: a tracing study using the B subunit of the cholera toxin. Brain Res Bull 41:391-398.

Dusek JA, Eichenbaum H (1998) The hippocampus and transverse patterning guided by olfactory cues. Behav Neurosci 112:762-771.

Ferreira MB, Da Silva RC, Medina JH, Izquierdo I (1992) Late posttraining memory processing by entorhinal cortex: involvement of NMDA and GABAergic receptors. Pharmacol Biochem Behav 41:767-771.

Izquierdo I, Da Cunha C, Rosat R, Jerusalinsky D, Ferreira MB, Medina JH (1992) Neurotransmitter receptors involved in post-training memory processing by the amygdala, medial septum, and hippocampus of the rat. Behav Neural Biol 58:16-26.

Jerusalinsky D, Ferreira MB, Walz R, Da Silva RC, Bianchin M, Ruschel AC, Zanatta MS, Medina JH, Izquierdo I (1992) Amnesia by post-training infusion of glutamate receptor antagonists into the amygdala, hippocampus, and entorhinal cortex. Behav Neural Biol 58:76-80.

Kublik E, Sara SJ (2003) Activity in medial frontal cortex during odour discrimination learning in the rat: neuronal response to experimental context. Eur J Neurosci [Suppl], in press.
Liang KC, Hon W, Davis M (1994) Pre- and posttraining infusion of $\mathrm{N}$-methyl-D-aspartate receptor antagonists into the amygdala impair memory in an inhibitory avoidance task. Behav Neurosci 108:241-253.

Liang KC, Hu SJ, Chang SC (1996) Formation and retrieval of inhibitory avoidance memory: differential roles of glutamate receptors in the amygdala and medial prefrontal cortex. Chin J Physiol 39:155-166.

Mayford M, Abel T, Kandel ER (1995) Transgenic approaches to cognition. Curr Opin Neurobiol 5:141-148.

McGaugh JL (1989) Dissociating learning and performance: drug and hormone enhancement of memory strorage. Brain Res Bull 23:339-345.

Morris RG, Anderson E, Lynch GS, Baudry M (1986) Selective impairment of learning and blockade of long-term potentiation by an $N$-methyl-Daspartate receptor antagonist, AP5. Nature 319:774-776.

Ongur D, Price J (2000) The organization of networks within the orbital and medial prefrontal cortex of rats, monkeys, and humans. Cereb Cortex 10:206-219.

Packard MG, Teather LA (1997) Posttraining injections of MK-801 produce a time-dependent impairment of memory in two water maze tasks. Neurobiol Learn Mem 68:42-50.

Paxinos G, Watson C (1986) The rat brain in stereotaxic coordinates. Sydney: Academic.

Roullet P, Bourne R, Moricard Y, Stewart MG, Sara SJ (1999) Learninginduced plasticity of $\mathrm{N}$-methyl-D-aspartate receptors is task and region specific. Neuroscience 89:1145-1150.

Santini E, Muller RU, Quirk GJ (2001) Consolidation of extinction learning involves transfer from NMDA- independent to NMDA-dependent memory. J Neurosci 21:9009-9017.

Sara SJ, Roullet P, Przybyslawski J (1999) Consolidation of memory for odor-reward association: beta-adrenergic receptor involvement in the late phase. Learn Mem 6:88-96.

Shimizu E, Tang YP, Rampon C, Tsien JZ (2000) NMDA receptordependent synaptic reinforcement as a crucial process for memory consolidation. Science 290:1170-1174.

Tronel S, Sara SJ (2002) Mapping of olfactory memory circuits: regionspecific c-fos activation after odor-reward associative learning or after its retrieval. Learn Mem 9:105-111.

Tsien JZ, Huerta PT, Tonegawa S (1996) The essential role of hippocampal CA1 NMDA receptor-dependent synaptic plasticity in spatial memory. Cell 87:1327-1338.

Wittenberg GM, Tsien JZ (2002) An emerging molecular and cellular framework for memory processing by the hippocampus. Trends Neurosci 25:501-505.

Zanatta MS, Schaeffer E, Schmitz PK, Medina JH, Quevedo J, Quillfeldt JA, Izquierdo I (1996) Sequential involvement of NMDA receptordependent processes in hippocampus, amygdala, entorhinal cortex and parietal cortex in memory processing. Behav Pharmacol 7:341-345. 